\title{
Caracterizacao físico-quimica de blends de cafés das variedades Arábica e Robusta.
}

\author{
Filipe Calixto Santos Patrocínio ${ }^{1}$; Luiz Severo da Silva Junior ${ }^{2}$; \\ 1. Bolsista PIBIC/CNPq, Graduando em Engenharia de Alimentos, Universidade Estadual de Feira de Santana, e- \\ mail: patrocínio.filipe@gmail.com \\ 2. Orientador, Departamento de Tecnologia, Universidade Estadual de Feira de Santana, e-mail: severo@uefs.br
}

PALAVRAS-CHAVE: Físico-químicas, Qualidade, Blends

\section{INTRODUÇÃO}

O trabalho é baseado no estudo das características físico-químicas obtidas por diversos níveis de blendagens, de cafés consumidos no estado da Bahia. O objetivo da pesquisa é avaliar através dos resultados de algumas analises físico-químicas, as quantidades de café arábica e robusta, que esta sendo praticada nas marcas comercializadas na cidade de Feira de Santana, como forma de evitar atitudes fraudulentas, quando se comercializa produtos com denominações de $100 \%$ de café arábica.

Realizamos os possíveis parâmetros de validação nas análises físico-químicas de pH, cinzas, umidade, acidez titulável, lipídios, resíduo seco. Os parâmetros empregados foram repetibilidade, reprodutibilidade e robustez.

Espera-se com a pesquisa, contribuir com os padrões de qualidade dos cafés consumidos na cidade de Feira de Santana, assim como, disponibilizar uma metodologia analítica eficiente na detecção de produtos adulterados.

\section{MATERIAL E MÉTODOS}

Foram coletadas amostras de cafés de lotes recentes comercializados nos supermercados de Feira de Santana.

Foram realizadas análises físico-químicas da bebida recentemente preparada como: $\mathrm{pH}$, cinzas, umidade, cafeína, acidez titulável, lipídios e resíduo seco. Todas essas análises foram realizadas por métodos oficiais do livro Métodos Físico-Químicos para Análise de Alimentos, e validadas pelos parâmetros da repetibilidade, reprodutibilidade, e robustez

As amostras dos cafés arábica e robusta foram preparadas de acordo a norma internacional ISO Guide 43-1 (United States of America, 1993, 1995; Switzerland, 1997) e a IUPAC.

As amostras de café torrados, moídos das duas variedades, foram homogeneizadas em homogeneizador do tipo Y (TECNAL), nas seguintes proporções: 100:0; 95:5; 75:25; 50:50, 25:75, 5:95 e 0:100, de café arábica e robusta, respectivamente.

Todas as análises físico-químicas do pH, umidade, lipídios, acidez titulável, resíduo seco, cinzas e cafeína, foram feitas pelos Métodos Físico-Químicos para Análise de Alimentos - 4ạ Edição - 1a Edição Digital- 2008.

\section{RESULTADOS E/OU DISCUSSÃO}

Os resultados obtidos permitiram observar diferenças significativas para todas as variáveis analisadas dos diferentes blends entre o café arábica e o café conilon nas amostras das duas marcas comerciais de café torrado e moído comercializado na cidade de Feira de Santana - BA. Nos quais foram avaliados índices de umidade, acidez titulável, cinzas, resíduo seco, $\mathrm{pH}, e$ cafeína. Todas as amostras foram mantidas em condições iguais todas foram armazenadas em potes de vidro fechados e protegidos da luz e umidade. 


\begin{tabular}{|c|c|c|c|c|c|c|c|c|}
\hline \multicolumn{2}{|c|}{ Blends ( \%) } & \multicolumn{7}{|c|}{ Análises Físico - Químicas } \\
\hline Arábica & Conilon & $\begin{array}{c}\text { Cinzas } \\
(\% \mathrm{~m} / \mathrm{m})\end{array}$ & $\begin{array}{l}\text { Umidade } \\
(\% \mathrm{~m} / \mathrm{m})\end{array}$ & $\begin{array}{l}\text { Cafeína ( } \\
\mathrm{mg} / \mathrm{mL} \text { ) }\end{array}$ & $\begin{array}{l}\text { Lipídios } \\
\text { (\% } \mathrm{m} / \mathrm{m})\end{array}$ & $\mathrm{pH}$ & $\begin{array}{c}\text { Acidez } \\
\text { titulável } \\
(\% \mathrm{v} / \mathrm{m})\end{array}$ & $\begin{array}{c}\text { Resíduo } \\
\text { Seco (\% } \\
\mathrm{m} / \mathrm{v}) \\
\end{array}$ \\
\hline 100 & 0 & $\begin{array}{c}3,977 \pm \\
0,075\end{array}$ & $\begin{array}{c}5,504 \pm \\
0,070\end{array}$ & $\begin{array}{c}0,010 \pm \\
0,0\end{array}$ & $\begin{array}{c}17,303 \pm \\
2,066\end{array}$ & $\begin{array}{l}5,13 \pm \\
0,082\end{array}$ & $\begin{array}{c}18,333 \pm \\
1,051\end{array}$ & $\begin{array}{c}2,556 \pm \\
0,023\end{array}$ \\
\hline 95 & 5 & $\begin{array}{c}4,106 \pm \\
0,039\end{array}$ & $\begin{array}{c}5,512 \pm \\
0,210\end{array}$ & $\begin{array}{c}0,0093 \pm \\
0,0\end{array}$ & $\begin{array}{c}6,938 \pm \\
4,693\end{array}$ & $\begin{array}{l}5,06 \pm \\
0,035\end{array}$ & $\begin{array}{c}17,661 \pm \\
0,504\end{array}$ & $\begin{array}{c}2,185 \pm \\
0,011\end{array}$ \\
\hline 75 & 25 & $\begin{array}{c}4,135 \pm \\
0,132\end{array}$ & $\begin{array}{c}4,864 \pm \\
0,005\end{array}$ & $\begin{array}{c}0,0097 \pm \\
0,0\end{array}$ & $\begin{array}{c}3,883 \pm \\
3,883\end{array}$ & $\begin{array}{l}5,15 \pm \\
0,015\end{array}$ & $\begin{array}{c}17,156 \pm \\
0,0\end{array}$ & $\begin{array}{c}2,301 \pm \\
0,007\end{array}$ \\
\hline 50 & 50 & $\begin{array}{c}4,198 \pm \\
0,161\end{array}$ & $\begin{array}{c}4,218 \pm \\
0,147\end{array}$ & $\begin{array}{c}0,0108 \pm \\
0,0\end{array}$ & $\begin{array}{l}9,84 \pm \\
1,532\end{array}$ & $\begin{array}{l}5,34 \pm \\
0,011\end{array}$ & $\begin{array}{c}15,138 \pm \\
0,0\end{array}$ & $\begin{array}{l}2,48 \pm \\
0,009\end{array}$ \\
\hline 25 & 75 & $\begin{array}{c}4,460 \pm \\
0,081\end{array}$ & $\begin{array}{c}3,738 \pm \\
0,140\end{array}$ & $\begin{array}{c}0,0112 \pm \\
0,0\end{array}$ & $\begin{array}{c}9,688 \pm \\
2,458\end{array}$ & $\begin{array}{l}5,43 \pm \\
0,015\end{array}$ & $\begin{array}{c}14,129 \pm \\
0,0\end{array}$ & $\begin{array}{c}2,432 \pm \\
0,008\end{array}$ \\
\hline 5 & 95 & $\begin{array}{c}4,510 \pm \\
0,066\end{array}$ & $\begin{array}{c}3,717 \pm \\
0,322\end{array}$ & $\begin{array}{c}0,0124 \pm \\
0,0\end{array}$ & $\begin{array}{c}9,581 \pm \\
9,581\end{array}$ & $\begin{array}{l}5,57 \pm \\
0,003\end{array}$ & $\begin{array}{c}14,969 \pm \\
0,291\end{array}$ & $\begin{array}{c}2,826 \pm \\
0,924\end{array}$ \\
\hline 0 & 100 & $\begin{array}{c}4,528 \pm \\
0,077\end{array}$ & $\begin{array}{c}3,769 \pm \\
0,780\end{array}$ & $\begin{array}{c}0,0137 \pm \\
0,0\end{array}$ & $\begin{array}{c}6,776 \pm \\
0,556\end{array}$ & $\begin{array}{l}5,75 \pm \\
0,026\end{array}$ & $\begin{array}{c}13,456 \pm \\
0,582\end{array}$ & $\begin{array}{c}3,575 \pm \\
0,002\end{array}$ \\
\hline
\end{tabular}

Tabela 2 - Análises Físico - Químicas de duas marcas distintas

\begin{tabular}{|c|c|c|}
\hline $\begin{array}{c}\text { Análises Físico - } \\
\text { Químicas }\end{array}$ & Marca no 1 & Marca no 2 \\
\hline $\mathrm{pH}$ & $6,293 \pm 0,038$ & $5,963 \pm 0,038$ \\
\hline Acidez titulável (\% v/m) & $2,52 \pm 0,0$ & $3,89 \pm 0,062$ \\
\hline Resíduo Seco (\% m/v) & $2,062 \pm 0,044$ & $2,091 \pm 0,008$ \\
\hline Cinzas $(\% \mathrm{~m} / \mathrm{m})$ & $5,431 \pm 0,036$ & $4,666 \pm 0,049$ \\
\hline Umidade $(\% \mathrm{~m} / \mathrm{m})$ & $3,572 \pm 0,036$ & $2,078 \pm 0,035$ \\
\hline Cafeína $(\mathrm{mg} / \mathrm{mL})$ & $\begin{array}{c}0,0112 \pm \\
0,000035\end{array}$ & $0,0109 \pm 0,000023$ \\
\hline Lipídios (\% $\mathrm{m} / \mathrm{m})$ & $9,239 \pm 1,497$ & $15,634 \pm 1,511$ \\
\hline
\end{tabular}

O teor de cinzas em café arábica comumente é menor em relação ao café conilon (CONTI et al., 2013). De acordo com a legislação vigente, o máximo de teor de cinzas que podem estar presente é de $5 \%$ (BRASIL, 1998). De acordo com esta pesquisa, apenas a marca no 1 esteve acima do valor de $5 \%$, demonstrando ser um produto com mais impurezas e de menor qualidade.

O teor de umidade do café pode afetar as características da amostra, a preservação do produto e principalmente o aroma, sendo um importante índice de qualidade (MORGANO et al., 2008). Todas as duas marcas ficaram abaixo de $5 \%$ de umidade, o indicado pela ANVISA para estar dentro do padrão.

Para a cafeína a Portaria n 377, de 26 de abril de 1999, fixa o teor mínimo de 0,7\% de cafeína no café torrado e moído (BRASIL, 199). As marcas $n^{\circ} 1$ e no 2 estão de acordo com os valores estipulados pela legislação vigente que determina no mínimo $0,7 \%$ de cafeína no café torrado e moído. 
Os lipídios possuem um efeito benéfico na qualidade da bebida do café, pois, durante a torração, concentram-se nas áreas externas, formando na semente uma camada protetora contra eventuais perdas ocasionadas pelo processo (PIMENTA, 2003). A pesquisa mostra que entre as duas marcas analisadas, a marca $\mathrm{n} 02$ apresenta maior teor lipídico.

$\mathrm{O} \mathrm{pH}$ de café torrado deve estar entre 4,95 e 5,2 para estar sem excesso de acidez ou amargor (SIVETZ e DESROSIER, 1979). Todas as duas marcas analisadas nesta pesquisa apresentaram $\mathrm{pH}$ fora da faixa indicada por Sivetz e Desrosier, mostrando $\mathrm{pH}$ mais alto que o normal devido a variação da torra do grão, quanto maior o grau da torra, maior será o seu pH.

A acidez titulável em grãos de café pode variar de acordo com o nível de fermentação que ocorre nos grãos e também com os diferentes estádios de maturação deles, servindo como uma análise auxiliar para a avaliação da qualidade da bebida do café (COSTA e CHAGAS, 1997). O ponto de viragem foi estabelecido por método potenciométrico, entre o pH 8,2 e 8,3. As marcas $n^{\circ} 1$ e $n^{\circ} 2$ não tiveram diferença significativa entre elas, sugerindo que a acidez presente não influencia na qualidade.

O valor mínimo de sólidos solúveis (resíduo seco) é de $25 \%$ (INMETRO, 1998). Podendo ser alterado devido a adição de substâncias estranhas e minerais. Além disso, também pode variar a composição do café, de acordo com as variedades utilizadas, aumentando ou diminuindo o teor de resíduo seco. As marcas $n^{\circ} 1$ e $n^{\circ} 2$ tiveram valores abaixo do mínimo podendo então dizer que houve adição de substâncias estranhas e minerais.

\section{CONSIDERAÇÕES FINAIS}

A partir da pesquisa estudada, foi possível analisar as principais características físicoquímicas dos blends de grãos de café arábica e robusta, e estimar qual o blend que está sendo comercializado na cidade de Feira de Santana - BA. Levando em consideração a análise de cafeína, a marca $\mathrm{n}^{\circ} 1$ seria com um blend $75 \%$ conilon e $25 \%$ arábica, já a marca $\mathrm{n}^{\circ} 2$ seria com um blend de $50 \%$ conilon $50 \%$ arábica.

\section{REFERÊNCIAS}

BRASIL. Ministério da Saúde. Agência Nacional de Vigilância Sanitária. Estabelece normas para fixar a identidade e as características mínimas de qualidade do café torrado em grão e café torrado e moído. Diário Oficial da República Federativa do Brasil, Brasília, DF, 16 jan. 1998.

BRASIL. Portaria n 377, de 26 de abril de 1999. Estabelece normas para fixar a identidade e as características mínimas de qualidade do café torrado em grão e café torrado e moído. Diário Oficial [Republica Federativa do Brasil], Brasília. 29 abr. 1999, seção 1, n 80-E.

CONTI, M. C. M. D. et al. Características físicas e químicas de cafés torrados e moídos exóticos e convencionais. Boletim do CEPPA, Curitiba, v. 31, n.1, p. 161-172, 2013.

COSTA, L.; CHAGAS, S.J.R. Gourmets - Uma alternativa para o mercado de café. Inf. Agropecu. Belo Horizonte, v.18, n.187, p.63-67, 1997.

MORGANO, M. A.; FARIA, C. G.; FERRÃO, M. F.; BRAGAGNOLO, N.; FERREIRA, M. M. C. Determinação de umidade em café cru usando espectroscopia NIR e regressão multivariada. Ciência e Tecnologia de Alimentos, Campinas, v. 28, n. 1, p. 12-17, 2008

PIMENTA, C.J. Qualidade do café. Lavras: Ed. da Ufla, 2003. 304p. 
SIVETZ, M.; DESROSIER, N. W. Physical and chemical aspects of coffee. Coffee Techonology. Westpor, p. 527- 575, 1979. 